\title{
2. Social Pathologies, Reflexive Pathologies, and the Idea of Higher-Order Disorders
}

\section{by Arto Laitinen}

The so-called Anna Karenina principle suggests that all happy families are alike, but each unhappy family has its own unique way of failing to be happy. Is something similar true at the societal level of social pathologies and their opposite - the socially 'normal', 'healthy' or acceptable condition?

Is it so that there is one way for all social worlds to be well-functioning and legitimate, but many different ways for a social world to fall short and be 'pathological'? Or is it so that each social world can have its own unique criteria and measure of normality, as suggested by Canguilhem's (1991) classic work on individuals and by Axel Honneth's (2014b) reference to a society's own values operative in its social reproduction? Or, is it rather that social pathologies are all alike in sharing a structure, as suggested by Christopher Zurn's (2011) interpretation of Axel Honneth's writings?

This paper examines the powerful suggestion by Zurn that social pathologies of all sorts, as discussed in the tradition of critical theory and by Axel Honneth in particular, can be conceived as second-order disorders. These include pathologies of ideological recognition, maldistribution, invisibilisation, rationality distortions, reification and institutionalised selfrealisation. What is at stake, in his view, are 'constitutive disconnects between first-order contents and second-order reflexive comprehension of those contents, where those disconnects are pervasive and socially caused' (Zurn 2011).

In his response, Honneth suggests some qualifications, and has later on further developed his ideas on social pathologies, but for example in his Freedom's Right he approvingly refers to Zurn's analysis of social pathology. ${ }^{1}$ This is to some extent surprising in that the 'reflexive' structure of pathologies seems to fit 'reflexive' freedom more closely, which for Honneth is not yet 'social' freedom. While reflexive freedom takes place in the critical capacities of the individual, social freedom is embodied in the institutional reality. I will suggest that Zurn's analysis may capture 'reflexive pathologies' whereas social freedom should perhaps be accompanied by an account of social pathologies. ${ }^{2}$

Curiously, when Zurn goes through these cases, it becomes apparent that as he presents them they do not actually fit into his characterisation of pathologies as second-order disorders (see subsections 2.1-2.6 below). Does 
this mean that these cases are not social pathologies after all? Or does it rather mean that we should drop the assumption that social pathologies have a structure in common? I suggest it would be premature to conclude either way, before checking whether these cases of social pathology perhaps have a more complex structure in common (so that different aspects of the structure are more salient in different cases). This is the task of this essay: trying to build a rival, more multilayered and encompassing model of the structure of social pathologies.

This is then very much an attempt to further pursue the avenue of analysis that Zurn opened: to study whether these cases of social pathology have a shared structure. It turns out that the answer is quite complicated (see subsection 1). The structure that emerges is not as neat as Zurn's original suggestion, but of course, one should not aim at forcing complex phenomena into a structural strait-jacket merely for the purpose of neatness. Further, one may allow that perhaps other avenues for analysing social pathologies without an assumption of a shared structure may be more fruitful, but that will be another story. Whether this new model will turn out to be useful in understanding social evils as social pathologies will depend on how various other questions concerning social pathologies are answered, but here the purpose is merely to test the idea that various social evils can informatively be approached with a more complex model.

I will add to Zurn's analysis the idea of a 'third-order' disorder (related to the pre-emptive social silencing of criticism even when critical reflection takes place), and try to sort out the plurality of levels involved in Zurn's discussion - the idea that there are only first and second orders turns out to be misleading. ${ }^{3}$

\section{Candidate Aspects of Social Pathologies}

Christopher Zurn (2011) argues that the conceptualisation of second-order disorders is the key to the concept of social pathologies. According to him, it unifies the various kinds of pathologies that Honneth has analysed: pathologies of ideological recognition, maldistribution, invisibilisation, rationality distortions, reification and institutionalised self-realisation (Zurn 2011, 345). To repeat, what is at stake, in his view, are 'constitutive disconnects between first-order contents and second-order reflexive comprehension of those contents, where those disconnects are pervasive and socially caused' (Zurn 2011, 345-346).

The phrase 'contents' is ambiguous as to whether the first-order content is embodied in the social world, or in one's experiences and understandings; and whether the content already contains some 'disorder' or 'obstacle' in the social realm (or whether the disorder concerns the relation 
between the first and the second orders). Sometimes Zurn speaks about 'firstorder experiences and second-order reflexive understandings' (Zurn 2011, 346 , italics added), and sometimes he seems to refer to the social reality. Further, despite the clarity of this formulation, later on it is not clear which aspect of the constellation Zurn regards as socially caused: the first order experiences, the second order reflexive understandings, or merely the 'disconnect' between them. The suggestion to focus on pervasive and socially caused social ills is well motivated, and will be preserved in the rival proposal made in this paper, but the other elements of the suggested definition will be revised rather broadly.

Before going through the six different cases Zurn discusses, let me note the aspects that a rival conceptualisation should account for. The characterisation in terms of 'orders' of phenomena is not compulsory, the language of 'aspects' might be equally suggestive. I will distinguish four aspects, which may contain systematic and socially caused faults: ${ }^{4}$ (i) social evils in the (first-order) contents of social reality (whether or not the subjects' reflection on those faults is systematically blocked); (ii) distortions in one's first-order participation in, and experience and comprehension of the social reality, which arguably is constitutive of the social reality (again, whether or not the subjects' reflection on those faults is systematically blocked); (iii) faults, as Zurn suggests, in one's second-order reflection (concerning i \& ii) and further; (iv) blockades in the aspects of the social world which make it less receptive to reflectively formed critical insights - making a difference to whether these insights can effectively change social reality (that is, even if the subjects' reflection on those faults is not systematically blocked, there could be a 'third order disorder,' where the subjects' reflective second order understandings are pre-emptively deemed irrelevant for the social world). ${ }^{5}$

This suggests three places where a disconnect can be found: a) between the social world and participatory experiences (i \& ii); b) between these (i\&ii) and the second-order reflections (iii); and c) between critical second-order reflections and the social world to be reshaped (iv). Again, it is not clear why social pathologies should be found only in the middle case (b) as Zurn suggests. Further, the substantive faults matter also in cases where there is no such disconnect.

All in all, we can try to locate the socially produced pervasive social evil, 'social pathology' for short, in any of the four aspects, or any of the three loci of 'disconnects'.

\subsection{Faults Within the First Order Social Reality}

One broad class of social phenomena, which Zurn's suggestion seemingly puts aside, are the cases where there is simply something wrong with the 
(first-order) social reality. It has features which are unjust, undemocratic, cause suffering, prevent well-being, cause lack of freedom and autonomy, or prevent genuine solidarity. There can be oppression, misrecognition, exploitation, domination and brute coercion of various sorts even though the subjects can reflexively grasp these concepts - the fault need not lie in the disconnect between reality and reflection, but in the social reality itself. (Of course, it may help the oppressor if the oppression is ideologically disguised).

Let us call 'naked' the cases of oppression where the social or structural cause and the kind of suffering it causes are more or less out in the open for all to see. ${ }^{6}$ Here, the 'surface' (as opposed to deep) hermeneutical approach of Michael Walzer etc. may suffice as a form of critique. There is no 'disclosing' critique needed to the extent that the problems are apparent. Theoretical ambitions should not lead us to look away from the possibility of such obvious cases.

Typically obstacles to self-realisation and well-being have a connection to socially caused suffering (the first order experiences). We can think of these cases as forming an experiential continuum: some cause unbearable experiential suffering, some do not immediately feel that painful or agonizing, but nonetheless there is a felt reaction to the wrongness encountered. Especially in the cases which are not immediately existentially painful, a systematic distortion can take place in that one may give up some normative expectations (at the cost to one's self-respect or integrity perhaps), due to the pain of having expectations violated.

Note that there need not be anything reflective in the picture yet - it is just that the experience consists of a response to a social whole which has descriptive and normative properties, and the painfulness of the descriptive properties comes in a continuum, and so does the strength of normative wrongness. In the immediate responses, we can analyse the pain caused by the descriptive features, and the element of the moral emotional response. Not receiving one's fair share may create strong emotional responses even in cases where what one receives is pleasurable as such - it is just that one receives less than is adequate.

The tradition of critical theory is specialized in harder cases, where the source of suffering is not naked. For such easy-to-spot social evils, not much theory is required, and participants in their cognitive-affectivevolitional responses and reactive attitudes detect normative expectations immediately - humans are normatively demanding and sanctioning animals.

Importantly, however, some forms of oppression or domination would not work without the incapacitation of second-order reflection. Nevertheless, Zurn's suggestion may make a false generalisation from such cases in implying that all the traditional topics of critical social theory are 
such phenomena. ${ }^{7}$

I take it that the main reason why the disconnect between first-order contents and subjective reflection is a bad thing is that there is lot to be criticised in the social reality as it is. On the other hand, there may be more to the rationality of the social world than the participants easily grasp, as Hegel tirelessly emphasizes.

\subsection{A Disconnect Between the Social Reality and One's First-Order Comprehension Of It?}

One kind of disconnect could hold between social reality and one's firstorder comprehension of it. Various cases of anomie, of lack of suitable socialisation (see e.g. Durkheim 1893, Honneth 2014b), and so on, can lead agents to be disconnected cognitively, motivationally or practically from the operative social reality. In some cases, the agents may not appreciate the full value of what the rational social reality is like, and in other cases, they may not have appreciated the oppressiveness of the irrational social reality.

However, given that the comprehension or even imagination of the members is constitutive of social reality, at some level one must share the constitutive understandings. To illustrate, compare an ape and a human consumer at a grocery store (Tomasello 2009). The consumer must understand what grocery stores are all about to be able to be shop or to function in the social reality in general. The same goes for slave markets, labor markets, and being a housewife: a full first-order lack of understanding would make one unable to operate at all within these social settings. A chimpanzee would not know how to operate in a human reality unless taught to do so - that is, unless provided with the first-order understanding.

In the typical case, the participant shares certain constitutive understandings, which sustain the social practices in question: the participant is in a sense complicit in the existence of those practices, via his or her first order understandings and participation. This suggests that when the social reality is at fault, so are the participants' understandings. (This supports treating the 'first order contents' Zurn writes about as encompassing both the social reality and participants' first order experiences and understandings.)

Such phenomena as invisibilisation (and cases of brute coercion mentioned above) may bypass the victim's understandings, they may work so that the victim need not be complicit. ${ }^{8}$ Even when the socially invisible subjects speak out, they may be treated as air, and their utterances may be regarded as inconsequential (which will be relevant in the analysis of the 'third order disorders' below). However, cases of invisibilisation typically come with 'learnt self-invisibilisation': the agent taking on the role of being 
socially invisible. It would be harder to ignore or 'look through' a chimpanzee in the room than to 'look through' a self-invisibilising human (unless the chimp were in a cage, brutely coerced). ${ }^{9}$

One-sided invisibilisation and brute coercion are cases where the social reality itself is at fault, independently of the victims' understandings. A severe disconnect between the social reality and the agents' understandings does not prevent such phenomena from taking place. By contrast, cases where self-invisibilisation is involved (and cases where voluntary submission to coercion is involved) presuppose that the social reality functions via the victims' understandings. That the victim's understandings are at play does not mean that they are to blame: by contrast, it is often an even more egregious violation of the victims that they are forced into taking part in the social reality that violates their rightful claims.

\subsection{The Zurn Cases: The Disconnect Between First-Order Contents and Second- Order Reflection}

Given all this, we can interpret Zurn's point as taking for granted that social reality is constituted in and through the (first-order) participation, comprehension, imagination, volition and emotional patterns of the participants. While the theorists may know that these first-order ways of taking and treating the social contents actually are constitutive of the social reality, in Zurn's cases the participants' ability to critically reflect on them has been systematically blocked.

Zurn's analysis can be read in more or less 'inclusive' ways. In the least inclusive, 'restricted' reading, the social pathology consists in the second-order reflection being blocked and out of touch with the first order contents (whether these are located in the world or in the participants' mind).

In its most inclusive form, this analysis can be seen to contain four interrelated elements. ${ }^{10}$ Firstly, there is (first-order) oppression, domination or misrecognition taking place in the social world. Secondly, the first-order beliefs (of the victims) contribute to this oppression, domination or misrecognition (e.g. by serving the interests of the elite, by hiding the oppression, domination or misrecognition from sight). This is not so in cases of 'brute, naked power' where the oppression goes on independently of the victims' understandings, but in other cases it holds. Thirdly, at the secondorder level (beliefs about the origin of the first-order beliefs), the first-order beliefs are understood as natural, unchangeable, and are to be taken for granted, rather than created by social mechanisms: ${ }^{11}$ critical second-order reflection on the constitutive first-order contents (both in the social world and in the participants' conceptions) can also be blocked in other ways. Fourth, the idea may be that the very same social mechanisms uphold 
oppression, create the problematic first-order beliefs, and distort the second order understandings as well, e.g. by blocking reflection on the matter. Occasionally in Zurn's essay the social forces are seen to cause different elements, but on a most inclusive reading all of these are intended to be part of the picture. ${ }^{12}$ Here, the suggestion (distinctive to Zurn's approach) can still be that the disconnect between first order contents and second-order reflection is a necessary aspect of social pathologies, but not the sole aspect. (Even this inclusive Zurnian position can be criticized if the disconnect between first and second orders is not a necessary feature of social pathologies. The non-Zurnian encompassing view I defend below will drop this requirement as a necessary feature.)

\subsection{Third-Order Disorders?}

Even if the obstacles for critical reflection were removed, there could be further obstacles for effective social criticism. On the side of the subjects (a), there could be motivational or practical obstacles: the agents could be disciplined so that they ignore their second-order reflections perhaps as 'naïve' or 'utopian,' or as fit objects for ridicule. More importantly, on the side of the social reality (b), the situation could be such that effective criticism is pre-empted, critical voices doomed to be silenced in advance, or the credibility or authority of the complaints taken away by default. This is the case where the views of the victims are deemed irrelevant, or where the victims have been robbed of a language in which to express the criticism. ${ }^{13}$ This can take various forms from literally labelling some people deranged, or taking some forms of complaints ('naïve' ones) as a sign that the person cannot be taken seriously, to merely ignoring them, making it institutionally the case that they are not being heard, or that their speech acts fall on deaf ears.

Again, typically the social world is constitutively tied up with the participants, so that socially pre-empting the critique (b) can be internalized in a form of self-censorship (a): as one knows in advance that criticisms will be socially labelled 'naïve', subjects may learn to sanction their critical thoughts by themselves, so that social silencing is not needed thanks to socially created self-silencing.

This is in a sense a 'third-order' disorder, as the assumption is that one's second-order reflection is intact and not cognitively out of touch with reality, but that one's motivation and possibilities to act on it have been preventively blocked. ${ }^{14}$ 


\subsection{Zurn's Restricted Definition Versus an Encompassing, Multilayered Structure}

There are accordingly three suggestions on the table concerning the structure of social pathologies. First, a restricted reading of Zurn's analysis, which includes only second-order disorders as social pathologies. Second, an inclusive reading of Zurn's analysis in which the second-order disorder is not everything there is to social pathology, but for which the second-order disorder is a necessary element. Against these, the third suggestion is nonZurnian in dropping the suggestion that any aspect is strictly speaking necessary for something to count as a social pathology, and in adding the third order disorders to the picture. This amounts to an encompassing multilayered structure, which captures the different aspects of social pathologies while claiming that different social pathologies may differ in the aspect in which things go wrong. All three accounts can focus on pervasive and socially produced phenomena. We can next take a brief look at pathologies of ideological recognition, maldistribution, invisibilisation, rationality distortions, reification, and institutionalised self-realisation to see how they fare according to the third proposal.

\section{Candidate Cases of Social Pathology}

\subsection{Ideology and Ideological Recognition}

In Zurn's reconstruction, the Marxian concept of ideology 'investigates firstorder beliefs, especially those about the basic structures, orders and functionings of the social world, and argues that social actors suffer from a cognitive pathology to the extent that they are not cognisant of how those beliefs come about' (Zurn 2011, 347, italics added). The participants are not aware that these beliefs are 'shaped by predominant social powers and classspecific social interests'(ibid.). That is, they lack certain true second-order beliefs (and presumably have false ones instead). This suggests that Zurn has the restricted definition in mind: it is precisely the socially produced lack or distortion of the second order reflection about the origins of first order views that deserves the title of 'ideology' or 'social pathology'. For example, 'a belief that wealth in capitalist societies is dependent entirely on one's individual initiative rather than the amount of capital at one's disposal is an ideological belief' (ibid.).

On the other hand, Zurn could be putting forward an encompassing definition, which has the whole structure in view: (i) the bad features of the social reality; (ii) the possibly distorted or complicit, implicit and explicit first order views about it; and (iii) the absent or distorted second order reflection about the content and origins of the view; and I would further add 
(iv) the 'third' layer of preventive obstacles for critical thoughts stopping them from ever becoming effective. Something like this is perhaps at work in a quote suggesting that there is 'a fundamental disconnect between firstorder contents and subjects' reflexive grasp of the origins and character of those contents, where that gap systematically serves to preserve otherwise dubious social structures and practices' (Zurn 2011, 348, italics added). That is, there are (i) otherwise dubious social structures and practices, (ii) first-order subjective contents (experiences, understandings) and (iii) subjects' reflexive grasp of the origins and character of those contents, and a gap between ii and iii. Further, Zurn in fact states that it is not only the second-order misunderstandings, but also the first-order attitudes and dispositions about social reality that are shaped by social powers and interests: ideology critique 'seeks to break the second-order sense of the naturalness and obviousness of participants' first-order beliefs, assessments, dispositions, behaviours, perceptions and interactions, by showing how many of these first-order contents are the specific results of socially determinate relations of power' $(2011,348$, italics added). Further, the criticism shows 'how subscribing to or acting in accord with these first-order contents contributes to the perpetuation of forms of domination, oppression and arbitrary inequality without the overt use of coercive mechanisms'(348). This in part goes to show that Zurn may have the more encompassing predicament in view.

Zurn also applies his understanding of ideology to recognition, in discussing Honneth's theory of ideological forms of recognition, which is at stake 'for instance, where a black slave is "recognized" for his subservience and submissiveness, a soldier is "recognized" for his heroic slaughters, or a housewife is "recognized" for her menial cleaning skills'(2011, 349).

Zurn again explicitly insists on the restricted reading:

without the second-order disorder, what we might generically call 'bad' acts of recognition (misrecognition, non-recognition) are not ideological and so cannot count as social pathologies. This analysis of ideological recognition then shares the same conceptual features as the classical concept of ideology identified above. (Zurn 2011, 349)

But again, on closer examination the other aspects of the more encompassing reading get emphasized as well. Zurn (2001, 349) sees as the key phenomenon 'widely shared social deformations of ... institutional processes of the formation and stabilisation of interpersonal recognitional evaluation. These deformations systematically serve certain social interests by maintaining systems of oppression without overt coercion. ${ }^{15}$ These processes are at the first order level, in social reality, and (to the extent that one 
participates in them) in one's participation in these processes of recognition.

For clarity, I removed the words 'second-order processes, namely' from the quote above. It is a symptom of Zurn's difficulties in sticking to his restricted proposal that he attributes the idea of second-order processes in a somewhat unprincipled manner. While Zurn's suggestion is to see a common structure in various negative things, the common structure is interpreted in different ways in different cases, and so it seems in places artificial to force the structure on the subject matter. Of course, second-order reflection could literally speaking take the processes of recognition as its object, and of course, such potential reflection can, as suggested by the restricted reading, be ideologically blocked.

Zurn's $(2001,349)$ attempts to clarify the issue lead to pretty complex constellations: he clarifies that he has in mind 'the processes whereby ideological recognition is naturalised,' processes that 'work by hiding or repressing the second-order disorders they cause.'

So here, what is naturalised is the first-order activity (a type of recognition in this case), and what is both caused and hidden or repressed is the second-order disorder (presumably in the restricted sense). So clearly, the second-order disorder in the restricted sense is merely one aspect of the undesirable constellation.

In a yet more complex formulation, social critique should

expose the social mechanisms that promote and perpetuate the widely shared patterns of ideological recognition while simultaneously hiding the mechanisms of second-order recognitional disorders from society's members behind a functional veneer of naturalised patterns of class and groupdifferentiated recognition. (Zurn 2011, 348-349)

This is very complex, read literally. Social mechanisms of the first type do two things simultaneously: they promote ideological recognition and hide mechanisms of another type. ${ }^{16}$ This is again indirect support for the encompassing view: there are indeed socially produced evils at different levels (in the social reality, in the first order responses, in the second order reflection, and in the third order obstacles to turning the critical reflection, if it takes place, into effective social protest). Zurn's paper forcefully brings these evils into focus, and in doing so, clearly has a more encompassing picture in mind despite explicit endorsement of the restricted reading. 


\subsection{Unjust Distribution of Rewards and Esteem}

Next Zurn discusses cases of 'Maldistribution as Distortions of Esteem Dispositives.' He refers to Honneth's (Deweyan) view of democracy as social cooperation, and to his view of social esteem as an adequate response to the contributions of individuals in a division of labour.

In this sphere, the problem emerges when individuals' capacities and contributions are not recognized or remunerated:

This can be seen where the division of labour relies, at the firstorder level, on the specific capacities and contributions of diverse individuals, but they are not accorded the appropriate recognition for their social contributions. Concretely, according to Honneth, this occurs where patterns of remuneration - the wages, salaries, benefits, and so on that are the media of recognition in a formal economic system - are not justifiably related to the actual first-order patterns of socially valuable work. Distributive injustice, then, is one form of more general second-order disorders in a democratic system of reflexive cooperation. (Zurn 2011, 351-2)

Note that here distributive injustice is characterised as a second-order disorder (a social pathology), rather than as some 'otherwise bad' practice taking place in social reality, to which first-order beliefs might contribute, and which would count as social pathology only in cases when the individuals' reflective understandings are systematically disconnected. It is rather clear that here the first and second orders are used differently from the previous cases. This is most obvious concerning recognition, which previously was located at the first level, here at the second. ${ }^{17}$

What Zurn here calls the first order is the activities within a division of labour, which presumably may contain its own injustices (say, the distribution of hard work can be unjust, or there may be wide-spread unwanted unemployment), whereas the second order consists of the patterns of remuneration and dispositives of social esteem. While these are of course 'second order' in the sense that they are about the social contributions made in the 'first order', they are part and parcel of the organization of the social reality. Democratic patterns of governing the reality are in a sense of a yet higher order of semantic ascent. However, all of this describes how the social practices and institutions are arranged, that is, the first aspect of the encompassing view, (i) above.

The next aspect of the encompassing view, (ii) the subjects' (firstorder) experiences and expectations of and participation in the tasks 
involved in one's role, and of the recognition one gets for one's contributions, are typically constitutive of the reality (again, compare to a chimpanzee in a supermarket, as opposed to the helping hand whose task is to help fill the shelves in the market). As Honneth has stressed, ordinary subjects are typically much better equipped to implicitly experience being wronged than to articulate these feelings of wrongness. For Honneth, an important role for critical theory and critical social movements is to try to provide such articulations. Whether one classifies such articulations as phenomena of the same order as, or a higher order than, the experiences that get articulated may be a matter of taste. What is relevant, however, is that the participants' experiences tend to contain the seeds of criticism.

(iii) The second-order reflection Zurn had in mind in the case of ideology comes to the fore when he speaks about the naturalisation and denaturalisation of society. The conceptions of social reality, of one's tasks in it and of the prevailing patterns of rewards may be held under the guise of how things are by nature, by necessities of some sort - this is the gap or disconnect between the first order contents and second order reflection discussed above. The paradigm cases of ideological recognition (a slave 'recognised' for their subservience and submissiveness and so on) seem to be cases like this, as do conceptions of the 'economy' (including patterns of remuneration) as a norm-free system which it would be pointless to criticize. The restricted reading should focus on this aspect alone, and indeed there is lot to criticise in that respect in contemporary society.

Lastly (iv) the 'third order' obstacles that are important for understanding the relative lack of effective public protests in the face of contemporary injustices in economic distribution, or contemporary deficits of democracy, are formed by the pre-emptive silencing of protests: just think of the way demonstrations against the contemporary economy are often framed in the mainstream news.

The 'restricted' reading would stress the naturalisation of the societal processes as the sole 'pathological' feature, but in his discussion of distortions of esteem dispositives, Zurn (inadvertently) shifts the way he applies the first-order - second-order conceptualisation. The benefit of the 'encompassing' reading is that these different levels are at play, so that such inadvertent changes in how the different 'orders' are conceptualized do not take place.

\subsection{Invisibilisation and Self-Invisibilisation}

Next Zurn turns to Honneth's analyses of invisibilisation, 'social processes of denigration that involve "looking through or past" another person' (Zurn 2011, 352). Here Zurn locates the portable conceptual device of first and 
second order in yet another location, between two forms of recognising others: 'social invisibility, especially of persons of denigrated castes, races and classes, involves an actual form of acknowledgement at a first-order level, but a non-acknowledgement of the person at the second-order level'(idem.).

Zurn adds two further conditions: that the

disregard of another is essentially active, involving the activity of purposefully ignoring or looking through another, and this presupposes that one has actually taken cognizance of the presence of the other in order to deny them the normal recognition that others are due as fellow persons. Finally, to be a social pathology, active disregard must be essentially connected to social patterns, here caste-like patterns of groupspecific denigration. (Zurn 2011, 352)

The idea that social pathologies are connected to social patterns is certainly worth stressing, and the 'encompassing' reading should sustain that. But what if the disregard is not active, but 'innocently' ideological? If so, then it does not fit Zurn's structure, but there are no compelling reasons to treat such cases differently - so perhaps the activity-condition should simply be dropped.

Zurn admits that in the case of invisibilisation, it is not the victim whose (second-order) attitudes count (which is yet another sign that the idea of second-order disorders is being used rather flexibly). ${ }^{18}$ However, Zurn here ignores the phenomenon of self-invisibilisation, which is crucial for invisibilisation (illustrated above: it is harder to 'look through' a chimpanzee in a room; just like it is harder to 'look through' a wolf than it is to look through a trained pet dog). It seems that successful practices of invisibilisation presuppose trained, formed, disciplined subjects, who know how to play the role of an invisible presence. Thus, importantly, in the case of invisibilisation and self-invisibilisation we have a pathological formation, which is here as well the work of both parties, the dominating and the dominated alike. And again, it can be ideologically naturalised, suggesting that the kind of disconnect between reflection and first order contents that the restricted reading would stress can be found in this case as well.

Importantly for the idea of 'third order disorder,' the silencing or preempting of critical voices shares the very pattern of invisibilisation: certain kinds of social criticism may be doomed to be ridiculed so that the message will not be heard - it amounts to the same as no speech act at all. So again, all the aspects of the encompassing view prove to be potentially relevant: (i) practices of invisibilisation in social reality, (ii) the participants' constitutive 
self-invisibilisation that sustains such practices in many cases, (iii) the possibly blocked reflection on it as the practices are treated as 'natural', and (iv) the pre-emptive measures immunizing the social reality from certain type of criticism by making the criticism invisible and inaudible.

\subsection{Pathologies of Reason}

In the tradition of critical theory, the central theorists 'consider present social pathologies to be fundamentally connected to distortions in rationality' (Zurn 2011, 353).

The disorders here are, first, that the first-order level of the extant social institutions does not reflect the potential of the second-order level of historically available rationality and, second, that even that rational potential is not widely shared and accepted as socially relevant by society members. (Zurn 2011, 353)

Again, the first and second orders are here understood slightly differently from the cases above: the social institutions are the first order phenomena, whereas then the standards of reason are of the second-order. This suggests that Zurn is indeed approaching the matter from the viewpoint of 'reflective freedom' of individuals rather than 'social freedom' embodied in institutions.

The Hegelian tradition to which much of critical theory belongs, including Honneth, would stress that the social institutions embody, actualize, and realise reason, to a higher or lower degree. The deficits and social evils in the 'first-order' social institutions, which are not as they ought to be, which do not actualise reason to the extent they could, are a matter of the features of the first order social reality. It sounds more like a version of Kantian dualism to locate the standards of rationality outside the social reality, as a phenomenon of a different 'reflexive' order. In the Hegelian view, reason is to a better or worse degree embodied in the social reality itself, and the latent potentials for critical reflection are conditioned by the prevailing social reality.

So, degrees of rationality characterise the first order contents (i) in the social reality and (ii) in the participants' often partial understandings and inarticulate experiences. Of course, there are also (iii) explicit processes of reflection on the second-order level, and it is important to analyse hindrances to these. Honneth's writings often stress the difficulty of unearthing what reason demands, the uncertain process of explicating some demands of rationality, which are in principle available and inchoately felt but demand 
articulation. In one sense, the critical insights are 'available' only for someone willing to do a lot of critical work: in another sense they are 'publicly available' only after someone has articulated them.

This distinction between rational insights being 'available through critical reflection' and 'publicly available' brings up (iv) what I have here called the 'third order' obstacles, namely obstacles that prevent someone's critical insights from leading to effective protest: Zurn in fact brings up one such obstacle, namely that the critical insights are not widely shared. ${ }^{19}$ Indeed, I would add that fully valid critical insights may seem irrational, obviously false, or ridiculous from the viewpoint of the historically conditioned common sense or the hegemonic discourse, insofar as the criticisms challenge their central dogmas. ${ }^{20}$

\subsection{Reification}

Next Zurn turns to an analysis of reification:

Honneth argues that the concept of reification can be productively reanimated today under changed theoretical and historical conditions by understanding acts of reification as actions in which an objectivating stance to others, the world or the self is adopted, while simultaneously forgetting the constitutive connections that such an objectivating stance has to our practical, interested and normatively laden interactions with others. (Zurn 2011, 355)

One would expect that cashing this out in terms of first- and secondorder phenomena would refer to the primordial normatively laden interactions as the first order contact with reality, making possible the objectifying cognitions at the second order. The problem could simply be that the objectifying stances contradict the primordial first order understandings of others and the world as significant, not as mere things. Zurn however applies this conceptual device differently (again attesting to the malleability of enumerating 'levels' or 'orders'):

the social pathologies of reification represent second-order disorders: first-order objectivating cognitions and interactions (whether of and with other persons, one's own feelings and dispositions, or the objective world) are disconnected from a second-order grasp of them as temporally and conceptually dependent on a prior act of recognition, yielding reifying cognitions and interactions properly speaking. The metaphor 
of forgetting here essentially refers to a second-order disorder. (Zurn 2011, 357)

Thus, for Zurn there is something prior to the first-order phenomenon: a prior act of recognition precedes and makes possible the first-order objectification and reification; and a second-order grasp that is critical of such objectification (and true to the prior acts of recognition) is simply missing. Again, the encompassing view with a plurality of foci would escape the strait-jacket of only counting to two in enumerating the relevant levels or aspects. Things can be at fault in (i) social practices containing objectification, (ii) the participants' non-reflective objectifying cognitions in tension with their practical involvements, and (iii) their reflective understandings. Finally, the patterns of reification may serve to (iv) block in advance any criticism, even when a reflective critical standpoint is formed, from being effective. (Perhaps the critics are reified or objectified as things of a certain kind, from whom certain lamentations are to be expected, and whose 'critic talk' is portrayed as what critics produce rather mechanically, however good the society in question. Perhaps the critic is female, or from this or that minority group, or an out-of-touch intellectual, so that patterns of reification can at the same time serve as patterns that silence criticism.)

\subsection{Paradoxes of Individualization}

The final illustration that Zurn tackles concerns the paradoxes of institutionalised individualisation, analysed by the institute of social research under Honneth's guidance. In contemporary worklife there is an institutionalised demand that one engage one's work with one's full subjectivity, and that one find self-realisation through one's work. This was originally a demand made by an 'artistic' critique of capitalism (as analyzed by Boltanski and Chiapello), but has been endorsed and institutionalised in distorted forms in contemporary worklife. There is a requirement and an assumption that one regard one's work as one's pet project, an authentic calling as it were. But of course, as a demand from the employer it cannot help taking inauthentic forms.

This form of institutionalised individualism in turn has led to pathological symptoms of psychological feelings of individual emptiness, meaningless and purposelessness on the one hand, and sociological symptoms of a pervasive ideology of personal responsibility that leads to neo-liberal deinstitutionalisation on the other. (Zurn 2011, 359) 
So, while new forms of labor are in principle friendly towards the idea that work should be a form of self-realization, this takes distorted forms: on the one hand the material conditions of real autonomous self-realization are not being provided (and so, to some extent, the promise or even imperative remains mere lip-service), and on the other hand one's subjectivity is all the more deeply at the service of the capitalist system.

This new constellation embodies, again, in different ways, obstacles to achieving well-being in the social reality, participants' first order conceptions of the reality, participants' reflective second order understandings and, finally, 'third order' obstacles to criticism leading to effective protests: here one obvious way in which criticism can be preempted is the paradoxical situation that the very ideal of authentic selfrealization has been appropriated by the new phase of capitalism.

\section{Conclusion}

In this essay I have made a number of negative claims. I have tried to show that the cases as discussed by Zurn do not actually fit into his characterisation of pathologies as second-order disorders. In Zurn's proposal the conceptual distinction between first and second order phenomena has turned out to be a kind of a portable conceptual device applied in very different ways in different contexts. Even Zurn's own interpretations of the six kinds of pathologies do not really support his claim that the central social pathologies share the structural feature of being second-order disorders (in the restricted sense).

A slightly better suggestion is the inclusive Zurnian reading suggesting that the faults are to be found in the social reality and in the first order experiences as well as in the second order reflection: this reading is still distinctively in the spirit of Zurn's suggestion, in that it can claim that the disconnect between first order contents and second order reflexion is a necessary, although not the sole defining feature of central social pathologies. But many of the cases discussed above do not match this pattern either.

Therefore I argued for an even more encompassing non-Zurnian view concerning social pathologies, which would include 'third order' disorders in the analysis. This view can also drop the requirement that any of the aspects are strictly speaking necessary for something to count as a social pathology. Whereas Zurn's proposal can be read as describing forms of 'pathologies of reflection' (analogous to reflexive freedom), the encompassing view is better seen as a candidate theory of 'social pathologies' (analogous to social freedom).

Here I have made the beginnings of a case for the view that nonetheless all the six cases discussed are indeed cases of social pathology, 
and that social pathologies can be analysed with the help of a more complex structure. The suggestion was that that structure is provided by the more encompassing view including (i) the multilayered social reality, (ii) firstorder participatory conceptions, (iii) second-order reflexive views and (iv) the patterns in social reality disabling in advance the effectiveness of critical views. This was the task of this essay: trying to build a rival, more multilayered and encompassing model of the structure of social pathologies. ${ }^{21}$

Arto Laitinen (arto.laitinen@uta.fi) is Professor of Social Philosophy at University of Tampere. He has a PhD from University of Jyväskylä, and an MA from University of Kent at Canterbury. He has been a researcher at University of Helsinki and a visiting scholar at Oxford University, University of Reading, Columbia University and University of Münster.

\section{Bibliography}

Boltanski, L \& Chiapello, E (2005) The New Spirit of Capitalism London: Verso Publishing

Canguilhem, G (1991 [1943/1966]) The Normal and The Pathological (trans. C. R. Fawcett \& R. S. Cohen) New York: Zone Books

Canivez, P (2011) 'Pathologies of Recognition' Philosophy and Social Criticism vol. 37 , no. 8, pp. 851-887

Durkheim, E (1947 [1893]) The Division of Labor in Society New York: The Free Press

Frankfurt, H (1971) 'Freedom of the Will and The Concept of a Person' Journal of Philosophy vol. 67 (lxvii), pp. 5-20

Freyenhagen, F (2015) 'Honneth on Social Pathologies: a Critique' Critical Horizons vol. 16, no. 2, pp. 131-152

Graeber, D (2011) Debt: The First 5000 Years New York: Melville House

Hegel, G. W. F. (1991 [1820]) Elements of the Philosophy of Right (ed. A. W. Wood, trans. H. B. Nisbet) Cambridge: Cambridge University Press 
Honneth, A (1995 [1992]) The Struggle for Recognition: The Moral Grammar of Social Conflicts (trans. J. Anderson) Cambridge: Polity Press

Honneth, A. (2011) 'Rejoinder' in D. Petherbridge (ed.) Axel Honneth: Critical Essays With a Reply by Axel Honneth Leiden: Brill, pp. 391-422

Honneth, A. (2014a) Freedom's Right: The Social Foundations of Democratic Life (trans. J. Ganahl) New York: Columbia University Press

Honneth, A. (2014b) ‘Diseases of Society: Approaching a Nearly Impossible Concept' (trans. A. Särkelä) Social Research: An International Quarterly vol. 81, no. 3, pp. 683-703

Lyotard, F. (1988 [1983]) The Differend: Phrases in Dispute (trans. G. van den Abbeele) Minneapolis: University of Minnesota Press

Neuhouser, F. (2000) Foundations of Hegel's Social Theory: Actualizing Freedom Cambrdige, MA: Harvard University Press

Neuhouser, F. (2013) 'Hegel on Life, Freedom, and Social Pathology' in A. Honneth \& G. Hindrichs (eds.) Freiheit Klostermann

Probst, B. (1989) 'Pathologie' Historisches Wörterbuch der Philosophie (ed. K. Gründe) pp. 182-191

Rorty, R. (1989) Contingency, Irony, Solidarity Cambridge: Cambridge University Press

Tomasello, M. (2009) Why We Cooperate Cambridge, MA: MIT Press

Zurn, C. F. (2011) 'Social Pathologies as Second-Order Disorders' in D. Petherbridge (ed.) Axel Honneth: Critical Essays With a Reply by Axel Honneth Leiden: Brill, pp. 345-370

Zurn, C. F. (2015) Axel Honneth Cambridge: Polity Press

\section{Endnotes}

1 'In each case [Zurn] takes me to be dealing with second-order social disorders, because subjects take up false, inappropriate stances toward their relatively intact 'first-order' practices, habits and perceptions. I immediately agree to this surprising and extremely illuminating proposal in the case of 
my discussion of 'reification', 'invisibilisation', and 'unjust distribution'. These are indeed all higher-level hindrances on the adequate judgement, classification and articulation of everyday practices, yet I have trouble applying this proposal to my attempt to reformulate the concept of ideology in recognitional terms or determine the paradoxes of organised selfrealisation. In these cases my descriptions oscillate between observations of first-order and second-order disorders.' (Honneth 2011, 417).

${ }^{2}$ One question for any account of social pathology is whether a social pathology is a cumulative sum of socially caused individual pathologies, or whether it is the society that is 'ill' (and individual suffering merely its diagnostic guide) so that perhaps society can be ill without its members being ill. Or, even if a society cannot be ill when individuals are not, the question remains whether social pathology is nonetheless a distinct feature (there could be a sum of individual suffering, from other causes, without the society being in a pathological state). Interestingly, Honneth (2014b) explicitly regards 'social pathology' as a feature of a society, but in his construal of social freedom (2014a) he differs from Neuhouser (2000) in not regarding freedom as a feature of the society or social whole.

${ }^{3}$ Here one can draw on the extensive literature on Harry Frankfurt's (1971) concept of second-order desires, specifically on analytical takes on how to define different higher 'orders'.

4 Arvi Särkelä suggested that these correspond roughly to Hegel's phenomenological concept of spirit as the shape of a world. There we have the consciousness (i) of the objective world as an 'other' of consciousness, (ii) of self, that is of the first-order experiences of it and (iii) the self-conscious second-order reflection on $\mathrm{i}$ and ii, that is Reason, as well as (iv) the institutional complex (Sittlichkeit) of enabling and reproducing i, ii and iii.

${ }^{5}$ Note how the second-order obstacle seems to connote 'reflexive freedom', whereas we might get a more fully Honnethian picture that goes with 'social freedom' if we ask whether these critical insights can perhaps be turned into effective protests and social movements.

${ }^{6}$ Cf. Rorty, Contingency, Irony, Solidarity, p.63, fn.21.

7 Zurn's suggestion best captures the nature of ideology and ideology critique. It is a surprising claim that this is all that the tradition of critical theory claims to do. Zurn extracts the structure of 'pathology' from that of ideology, and in that sense reads all pathology as ideology. (I thank Arvi 
Särkelä for a comment on this.) This is explicit when he distinguishes between other bad forms of recognition and ideological ones, and states that the former are not ideological, and therefore not pathological: 'without the second-order disorder, what we might generically call 'bad' acts of recognition (misrecognition, non-recognition) are not ideological and so cannot count as social pathologies.'(Zurn 2011, 349). (see also Freyenhagen, 2015, for a criticism of this move.)

${ }^{8}$ These phenomena are related: invisibilisation can piggyback on coercion, and can complement aggressive behavior (say, in a war).

${ }^{9}$ Similarly, coercion can function through direct physical control of the other's body, but typically functions via threats - and in responding to threats there is some exercise of one's volition involved. If one does not understand the threat as a threat, one cannot really respond to it as a threat.

${ }^{10}$ Thanks to Hans Arentshorst for a related suggestion.

${ }^{11}$ Joonas Pennanen pointed out that there is no literal contradiction between first- and second-order beliefs insofar as they are not about the same thing; Zurn suggests there is a gap or 'disconnect' between the first and second orders. An anonymous referee suggested that the second-order beliefs need not concern only the social or natural origin of the first order beliefs, but can also be about their truth, falsity etc.

${ }^{12}$ Zurn is primarily interested in the social causes of the disconnect between the first and second orders, e.g. 'a critical social theory of social pathologies needs not only an accurate explication of pathological disorders at the level of personal experiences but also insightful sociological explanations of the causes of those pathological distortions.'

${ }^{13}$ Cf. Lyotard, The Differend.

${ }^{14}$ As a semantic point (cf. Harry Frankfurt's definition of second-order desires as desires about desires) one can say that when one thematizes, with Zurn, the socially produced disconnect between the first-order experiences and second-order reflection, one is engaged in a third-order discourse (about the first and second orders).

${ }^{15}$ Again, it is not easy to see what the second-order 'processes' allegedly at stake are. Presumably something 'governing' the first-order processes. It might be worth pointing out that what guides a first-order process need not 
literally be a process itself, but can be a structure of some sort (like traffic signs guide traffic without being 'processes').

${ }^{16}$ Perhaps the latter word 'mechanisms' can be dropped (in the same way that to use Constantine Sandis's example, in a construction 'the city of Paris', the 'city of' can be dropped) so that the first type of mechanism hides the second-order recognitional disorders, rather than the mechanisms that cause them.

${ }^{17}$ Perhaps the distinction between first and second-orders is a portable device for a theorist, rather than a structure in reality. There are more aspects in reality, and it depends on the case which of them is taken as the first and which as the second order. The benefit of the encompassing reading is that such moves can be avoided.

${ }^{18}$ Zurn adds optimistically that 'nevertheless, the same conceptual structure of a second-order disorder is evident, and critical social theory has a similar role in exposing and explaining it as a social pathology'(353).

${ }^{19}$ Admittedly, not being 'widely shared' may be different from being systematically blocked or hindered by some structural features.

${ }^{20}$ One such idea which invokes incredulous stares from some and yet are critical platitudes for others is the idea that sovereign debt is not straightforwardly governed by the moral imperative that debts should be paid back, the sooner the better. Chapter One in Graeber (2011) captures this nicely.

${ }^{21}$ I would like to thank members of the Pathologies of Recognition research project, and Chris Ferguson, and Alison Beale for extended critical and clarificatory comments and for help with the language. 